\title{
Models, Methods, and Evidence: Topics in the Philosophy of Science 38th Oberlin Colloquium in Philosophy
}

\section{April 4-6, 2008}

Each symposium is two hours long, with main papers lasting 50-60 minutes, comments lasting about 20 minutes, and the remainder reserved for open discussion.

All sessions will take place in Craig Lecture Hall, in the Science Center.

\section{Friday April 4th}

7:30 p.m. Speaker: Bas van Fraassen (Princeton University) "The Perils of Perrin, in the Hands of Philosophers" Commentator: Helen Longino (Stanford University) Chair: Martin Thomson-Jones (Oberlin College)

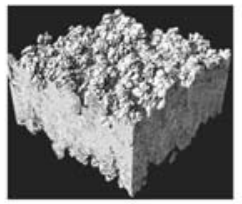

\section{Saturday April 5th}

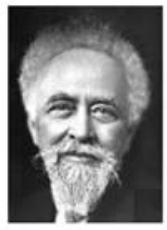

10:00 a.m. Speaker: Margaret Morrison (University of Toronto) "Models, Mediation, and Measurement" Commentator: Ronald Giere (University of Minnesota) Chair: Nick Huggett (University of Illinois, Chicago)

1:30 p.m. Speaker: Elliott Sober (University of Wisconsin, Madison)

"Absence of Evidence and Evidence of Absence"

Commentator: Michael Strevens (NYU)

Chair: Andrea Woody (University of Washington)

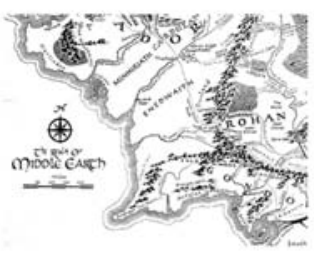

3:30 p.m.

Coffee break

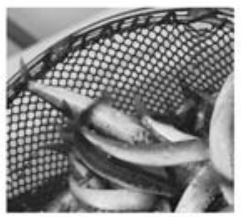

3:45 p.m. Speaker: Peter Godfrey-Smith (Harvard University) "Models and Fictions in Science" Commentator: Arthur Fine (University of Washington) Chair: Richard Healey (University of Arizona)

\section{Sunday April 6th}

10:00 a.m Speaker: Nancy Cartwright (LSE, UC San Diego) "Evidence-Based Policy: So, What's Evidence?" Commentator: Sherrilyn Roush (UC Berkeley) Chair: Kyle Stanford (UC Irvine)

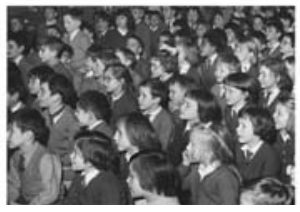

